\title{
ESTERILIZAÇÃO COMPULSÓRIA E O CASO DE JANAÍNA A LUZ DA LEI DO PLANEJAMENTO FAMILIAR № 9.263/96
}

\author{
Tatiane Nunes Rodrigues, UNIFSA ${ }^{2}$ \\ Izabel Herika Gomes Matias Cronemberger, UNIFSA ${ }^{3}$
}

\section{RESUMO}

O presente artigo tem como objetivo analisar a esterilização compulsória do ponto de vista da obrigatoriedade que fere a dignidade da pessoa humana e os direitos fundamentais da mulher, demonstrando a problematização da intervenção estatal de forma excessiva sobre o corpo feminino. Utiliza-se como metodologia o método dedutivo por meio de pesquisa bibliográfica, com aporte em doutores consagrados tais como Tartuce (2018), Dias (2016) e Lenza (2015), que discutem em livros e artigos, bem como pesquisa documental acerca da temática abordada. Para tanto, tem-se uma reflexão do não retrocesso à liberdade, à saúde e aos direitos adquiridos sobre o corpo feminino.

Palavras-chave: Esterilização. Planejamento Familiar. Intervenção Estatal.

\section{ABSTRACT}

This article aims to analyze the compulsory sterilization from the point of view of the obligation that hurts the dignity of the human person and the fundamental rights of women, demonstrating the problematization of state intervention in an excessive way on the female body. It is used as methodology the deductive method through bibliographical research, supported by well-known doctors such as Tartuce (2018), Dias (2016) and Lenza (2015), who discuss in books and articles, as well as documentary research on the subject. addressed. Therefore, there is a reflection of the non-regression to freedom, health and acquired rights over the female body.

Keywords: Sterilization. Family Planning. State Intervention. violence

\section{INTRODUÇÃO}

As reflexões desse estudo analisam a violência cometida contra Janaína Aparecida Quirino, mulher, mãe de cinco filhos e grávida do sexto, em situação de rua, que recebeu um mandato de condução coercitiva para a realização de esterilização,

\footnotetext{
${ }^{1}$ Trabalho apresentado no Congresso Brasileiro Ciência e Sociedade (CBCS 2019), promovido pelo Centro Universitário Santo Agostinho, de 03 a 05 de outubro de 2019, em Teresina-PI.

2 Bacharelanda em Direito pelo Centro Universitário Santo Agostinho - UNIFSA, Brasil. E-mail: tatianenusrodrigues@gmail.com

${ }^{3}$ Doutora e Mestre em Políticas Públicas pela Universidade Federal do Piauí, Brasil. Professora do Centro Universitário Santo Agostinho , Brasil. E-mail:izabel_herika@hotmail.com
} 


\section{CONGBESSO CIENCIAESOCIEDADE \\ Inovação, Diversidaale e Sustentahilitilade}

desrespeitando o direito a dignidade humana e todos os outros inerente a Constituição de um Estado Democrático de Direito.

Para Janaína de nada valeu o direito ao Planejamento Familiar resguardado na Lei no 9.263/96. A esterilização é um direito de todo cidadão, visto que decorre do princípio da dignidade da pessoa humana e do princípio da paternidade responsável previsto no artigo 226, $§ 70$, da CF/88 (LENZA, 2015). Todavia, é necessário ir além, esse direito deve ser acompanhado do preparo a educação em saúde sexual e reprodutiva, a informação dos métodos e técnicas de concepção e contracepção, a saúde do paciente esclarecendo os cuidados do antes e depois da cirurgia e a liberdade de escolha em realizar ou não o procedimento, sem nenhuma forma de coação ou julgamento.

É de competência do Estado regular e impor normas jurídicas, possuindo o direito ao planejamento familiar ordem governamental dotado de natureza promocional, ou seja, cabe ao Estado impulsionar e garantir a concretização dos direitos fundamentais acima citados, seja de forma comissiva, realizando ações através de políticas públicas assegurando tais direitos, ou de forma omissiva, mantendo-se inerte, não intervindo em certos casos para não restringir direitos impostos à vida privada (BRASIL, 1988).

Diante disso, foi editada a Lei do Planejamento Familiar no 9.263/96, em que regulamenta o $\S 70$ do artigo 226 da Constituição Federal, estabelecendo requisitos para a realização da esterilização, além dos impedimentos, penalidades e outras providências, a qual será objeto deste artigo (BRASIL, 1996).

Nesse sentido, o objetivo é analisar a esterilização compulsória do ponto de vista da obrigatoriedade que fere a dignidade da pessoa humana e os direitos fundamentais da mulher, com a problematização da realização do procedimento de forma coercitiva pelo Estado.

Para tanto, a discussão gira em torno do direito ao planejamento familiar, regulamentado pela Lei no 9.263/96, trazendo o reconhecimento dos direitos reprodutivos da mulher na Constituição Federal de 1988, sendo questionado principalmente o direito a laqueadura e seus requisitos. Também serão abordados 


\section{CONGEFESOCIENCIAESOCIEDADE \\ Inovação, Diversidaale e Sustentahilitilade}

breves comentários sobre a intervenção do Estado em relação à esterilização de forma coercitiva, e também será detalhado o caso de Janaína, relatando uma situação concreta de esterilização compulsória, como resultado de violência contra a mulher, resultando na afronta a todos os direitos discorridos no presente artigo. Por fim, tratando das considerações finais onde aponta a utilização do poder coercitivo e das prerrogativas do Estado na violação dos direitos por meio de atos manifestamente ilegais indo de encontro a Constituição e o Estado Democrático de Direito.

\section{METODOLOGIA}

A metodologia da pesquisa utilizada foi a abordagem dedutiva, pois se partiu de teorias e leis gerais às específicas, concepções e conceitos para se encontrar respostas ao problema abordado. A pesquisa caracterizou-se essencialmente como bibliográfica, onde buscou-se aporte teórico nos trabalhos de Tartuce (2018), Dias (2016) e Lenza (2015), que discutem em livros e artigos, bem como pesquisa documental para investigar os direitos fundamentais da mulher com a consequente intervenção do Estado na realização da esterilização segundo a Lei de Planejamento Familiar de no 9.263/96, Constituição Federal de 1988 e os Direitos Humanos.

O estudo ora apresentado lança mão de pesquisa bibliográfica e documental. No primeiro caso, trata-se de uma conjunção de procedimentos para "[...] identificar, selecionar, localizar e obter documentos de interesse para a realização de [...] pesquisas, bem como técnicas de leitura e transcrição de dados que permitem recuperá-los quando necessário", segundo palavras literais de Stumpf (2008, p. 54). A pesquisa documental, por sua vez, compreende identificação e análise criteriosa de documentos sobre o assunto em pauta para a consecução dos objetivos previamente definidos, no caso, pode-se citar a própria Constituição Federal de 1988, a Lei do Planejamento Familiar e outros (MINAYO, 2006).

Os procedimentos metodológicos adotados foram de cunho qualitativo, pois se preocupou em interpretar aspectos mais densos, descrevendo a complexidade dos processos sociais (MINAYO, 2006) que nesta, além da apreensão das técnicas, destaca- 


\section{CONGEFESOCIENCIAESOCIEDADE

se a percepção sobre a esterilização compulsória realizada pelo Estado. A reflexão foi analisada à luz da perspectiva teórico-metodológica crítica dialética.

\section{RESULTADOS E DISCUSSÕES}

A conquista aos direitos sexuais e reprodutivos teve um passo significativo em 1994 com a Conferência de Cairo, intitulada como Conferência Internacional de População e Desenvolvimento (CIPD), com a eliminação da ideia de que a população numerosa seria a causadora da pobreza e da miséria, com a concepção puramente econômica e financeira, passando a defender a melhoria da qualidade de vida e o respeito aos direitos sexuais e reprodutivos, como também a essencial interferência do Estado apenas na implementação de políticas públicas garantidora desses direitos. No Brasil, seguindo esse entendimento, introduziu o conceito de saúde e reprodução, principalmente no tocante ao planejamento familiar na Constituição Federal de 1988, como posteriormente com a edição da Lei do Planejamento Familiar no 9.263/96 (RAMOS, 2008).

Nesta esteira, a Constituição de 1988, reconheceu no artigo 226 , § 70 os direitos reprodutivos da mulher. O planejamento familiar seria um conjunto de ações que teria como finalidade auxiliar homens e mulheres a planejar de forma responsável a chegada dos filhos, ou então, prevenir gravidez não planejada (BRASIL, 1988), dessa forma, observa-se que o legislador deu total liberdade ao indivíduo para planejar sua família, competindo ao estado a sua abstenção na intervenção dos direitos reprodutivos.

Segunda Dias (2016) vale ressaltar que os métodos reprodutivos e técnicas de concepção e de contracepção é um direito de todo o cidadão e não apenas do casal.

O constituinte, sem dúvida alguma, proibiu a intervenção do Estado no planejamento familiar que cabe apenas ao indivíduo, entretanto, as autoridades públicas poderão proporcionar recursos para a concretização desses direitos. Nesse sentido, Pedro Lenza (2015) cita duas ações estatais: distribuição de preservativos, não só no carnaval, mas durante todo o ano, o que materializa o comando do art. 226, § 7으, 


\section{CONGEFESOCIENCIAESOCIEDADE

e distribuição da pílula anticoncepcional de emergência, também conhecida como pílula do dia seguinte, é um recurso anticoncepcional importante para evitar uma gravidez indesejada, após uma relação sexual desprotegida (LENZA, 2015, p. 1454).

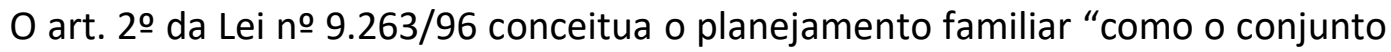
de ações de regulação da fecundidade que garanta direitos iguais de constituição, limitação ou aumento da prole pela mulher, pelo homem ou pelo casal" e em seu parágrafo único dispõe que "é proibida a utilização das ações a que se refere o caput para qualquer tipo de controle demográfico" (BRASIL, 1996), ou seja, não tendo qualquer intenção de controle de natalidade no país.

A lei também enfatiza o dever do Sistema Único de Saúde (SUS) de promover o treinamento de recursos humanos através de ações preventivas e educativas que garanta o acesso igualitário a informação, meios, métodos e técnicas disponíveis sobre o planejamento familiar, com ênfase na capitação do pessoal técnico visando à promoção de ações de atendimento à saúde reprodutiva (BRASIL, 1996).

A esterilização passa a ser tratada a partir do artigo 10 da lei, em que permite 0 método em homens e mulheres, em duas circunstâncias. A primeira quando possuir capacidade plena e idade mínima de vinte e cinco anos ou possuir pelo menos dois filhos vivos, desde que observado o prazo mínimo de sessenta dias entre a manifestação de vontade e o ato cirúrgico, neste período será proporcionado o acesso a serviço de regulação da fecundidade, incluindo aconselhamento por equipe multidisciplinar, com o fim de desencorajar a esterilização precoce. Segunda situação será quando à risco de vida ou à saúde da mulher ou futuro concepto, desde que testemunhado em relatório escrito e assinado por dois médicos (BRASIL, 1996).

Entretanto, como é que o Estado estabelece na Carta Magna que o planejamento familiar é de livre decisão do casal, se na própria lei que regulamentou o planejamento familiar limita a vontade do homem e da mulher estabelecendo requisitos de idade e de quantidades de filhos.

Cumpre ressaltar ainda, que $0 \S 50$ do mesmo artigo 10 da Lei, exige a autorização de ambos os cônjuge por escrito para a realização da esterilização, se esta for realizada na vigência do matrimônio. Importante destacar, que caso a manifestação 


\section{conghESSO CIENCIAESOCIEDADE

for expressa durante a ocorrência de alterações na capacidade de discernimento por influência de álcool, drogas, estados emocionais alterados ou incapacidade mental temporária ou transitória, será considerada nula (BRASIL, 1996).

A lei no 9.263/96, em seu capítulo II, irá tratar dos crimes e das penalidades da realização do método de esterilização. 0 artigo 15 considera crime a realização do procedimento cirúrgico em desacordo com os requisitos estabelecidos no artigo 10, já citado, com pena cominada de 2 a 8 anos de reclusão e multa, se a prática não constituir crime mais grave (BRASIL 1996), mesmo que esse médico realize o método fora dos padrões legais e receba sua punição não irá reparar o dano da vítima. Há casos em que o Poder Judiciário determina por meio de decisão judicial que o médico realize a cirurgia de laqueadura compulsoriamente tirando da vítima o direito de ter filhos, mesmo que o médico seja responsabilizado e cumpra a pena máxima cominada ao crime, a justiça será tardia, pois essa punição não reverterá o procedimento da laqueadura, quem viverá com a sensação de punição perpetua não será o médico, mas sim a paciente.

No limite da interferência do Estado a legislação garante a liberdade através do artigo 226, § 70 da Constituição Federal em que se funda nos princípios da dignidade da pessoa humana e paternidade responsável, determinando que o planejamento familiar é de livre decisão do casal. Ademais, funda-se também no principio da não intervenção do Estado no planejamento familiar, que esta intimamente ligada aos princípios da liberdade e da autonomia privada. O princípio da não intervenção é reforçado pelo art. 1.513 do Código Civil, declara que é defeso a qualquer pessoa, de direito público ou privado, interferir na comunhão de vida instituída pela família, por outras palavras, respeitada a liberdade de escolha da mulher, do homem ou do casal no que se refere ao seu planejamento familiar, como afirma o Doutor Flávio Tartuce (2018, p. 1324), o Estado não pode intervir, entretanto deverá incentivar nas relações familiares, como por exemplo, o planejamento familiar por meio de políticas públicas, através de recursos educacionais e científicos para o exercício do direito previsto na Constituição Cidadã. 


\section{CONQEEESSOCIENCIAESOCIEDADE

Porém, há casos em que a interferência do Estado é considerada abusiva, em decisões tão pessoais que diz respeito ao direito a reprodução, retirando a autonomia pessoal. Determinando que mulheres podres, moradoras de rua, e com certas quantidades de filhos sejam esterilizadas involuntariamente, ao invés de proporcionar recursos contraceptivos menos gravosos para evitar gravidez indesejada, seria uma preocupação a menos para o Estado, mas por outro lado, uma punição eterna para a mulher.

Assim, pode se dizer que "o papel do Estado aqui, embora ativo, limita-se à função promocional de 'propiciar recursos educacionais e científicos' para o seu exercício, de modo que todos estejam suficientemente informados e conscientes das maneiras pelas quais podem exercê-lo, respeitando os limites legais" (CANOTILHO, et al. 2013, p. 4595).

Deste modo, o governo poderá atuar ativamente, proporcionando recursos informativos, educacionais e científicos para auxiliar no planejamento familiar, não podendo, portanto restringir direitos e garantias fundamentais já estabelecidos na Constituição Federal.

E este é o ponto que passamos a tratar no item seguinte, um caso concreto de uma mulher que foi forçada a realizar o procedimento de esterilização, através de ação ajuizada pelo Ministério Público de São Paulo, em que foi julgada liminarmente. Uma decisão totalmente contrária aos fundamentos e princípios que embasam a ordem constitucional, extrapolando todos os limites vedados pela Constituição, considerando a mulher como um mero objeto processual, como será posto adiante nas reflexões do caso de Janaína.

Janaína Aparecida Quirino, moradora de rua foi levada por meio coercitivo pelo Estado, sem seu consentimento, para a realização de laqueadura tubária. Um ato manifestamente ilegal, por violar princípios inerentes à dignidade da pessoa humana e da vida privada, com abuso excessivo do Poder Judiciário por meio de medida liminar, que possuía visivelmente o pedido de limitação da prole da vítima, para obter o controle demográfico proibido por Lei Ordinária n 9.263/96 (VIEIRA, 2018). 


\section{CONQEEESSOCIENCIAESOCIEDADE

O caso veio a público através da coluna do Professor da Fundação Getúlio Vargas (FGV) Direito de São Paulo, Oscar Vilhena Vieira, pela Folha de São Paulo, em 9 de junho de 2018. Segundo Vieira (2018), Janaína Aparecida Quirino "não consentiu ou voluntariamente se prontificou a realizar a cirurgia, o promotor propôs duas ações judiciais contra ela e o município de Mococa, com o objetivo de constrangê-la a realizar um procedimento de esterilização compulsória", resultando claramente em abuso de autoridade por parte do promotor, utilizando-se da sua função para realizar um procedimento proibido por lei e desviando de suas finalidades.

De acordo com Oscar (2018), o juiz não nomeou defensor público, não designou audiência ou exigir documentos que comprovasse o consentimento de Janaína para a realização do procedimento, resultando em sua condução coercitiva. Quando o município de Mococa recorreu da liminar no Tribunal de Justiça, a reforma da decisão já era tardia, visto que o procedimento já teria acontecido.

Ademais, vale ressaltar que a medida coercitiva é admitida no ordenamento brasileiro, regulada pelo Código de Processo Penal no artigo 218 que prevê apenas a condução forçada de testemunhas que, regularmente intimadas, deixarem de comparecer sem motivo justificável ao juízo (BRASIL, 1941), visivelmente outra ilegalidade que abarca a histórica de Janaína.

Há a necessidade da vitima não ter dúvidas sobre o procedimento, não é expressar a manifestação de vontade apenas em um documento, a vítima tem que receber todas as informações necessárias, pontos negativos e positivos para se decidir sobre a realização ou não.

Oscar Vieira (2018) ainda destaca que o Promotor utilizou-se de uma ação civil pública, que é voltada para defender direitos difusos, coletivos e individuais indisponíveis, para forçar o Município a constranger uma mulher e realizar um procedimento manifestamente ilegal.

Importante destacar também que o artigo 129 da Constituição Federal, em seu inciso III, trata justamente da função institucional do Ministério Público a promoção da ação civil pública, para a proteção dos interesses difusos e coletivos (BRASIL, 1988), dessa forma, acrescenta-se mais um vício no caso de Janaína que resultaria na extinção 


\section{CONGEFSSOCIENCIAESOCIEDADE

do processo sem resolução do mérito em razão da carência da ação visto que o caso de Janaína não se enquadraria nos requisitos de cabimento da ação civil pública ajuizada pelo Ministério Público.

Conforme a Ação disponibilizada no site da Revista Fórum (2018), a sentença da 2a Vara da Comarca de Mococa julgou procedente a ação movida pelo Ministério Pública condenando o Município a realizar a laqueadura, objeto dos autos, assim que ocorrer o parto da requerida Janaína, o município inconformado com a sentença interpôs recurso de apelação no Tribunal de Justiça de São Paulo, com o fim de reverter o julgado e não realizar o procedimento de laqueadura, entretanto já era tarde visto que Janaína foi esterilizada no dia 14 de fevereiro de 2018 conforme ofício no 1581/2018 da Penitenciária Feminina de Mogi Guaçu, infelizmente, mais uma vez o Poder Judiciário decidiu de forma contrario aos preceitos da Constituição, julgando de forma parcial sem ao menos determinar um defensor ou designar uma audiência para instruir o processo e ter uma melhor visão do caso de Janaína, tratando-a como mero objeto processual.

Percebe-se que em comparação ao tema em análise, o Estado não age corretamente ao impor a esterilização, pois o planejamento familiar é um direito à informação, assistência especializada e acesso aos recursos que permita a mulher, optar de forma livre, consciente e voluntariamente em ter filhos (mais filhos) ou não, sem discriminação, coerção ou violência. Todavia, o caso de Janaína foi diferente, não sendo respeito nenhum direito resguardado a pessoa, nem mesmo o princípio da dignidade humana, foi considerado para embasar o pedido do Ministério Público as condições pessoais de Janaína, pelas dificuldades financeira, educacional, pessoal e vícios alcoólicos, fundamento que a legislação brasileira veda e condena, utilizar da via judicial para condenar aquele desfavorecido socialmente. É difícil analisar a atuação do Poder Judiciário, aquele que detêm o dever de defender os direitos fundamentais, foi o responsável por legitimar a subtração de direitos.

\section{CONSIDERAÇÕES FINAIS}




\section{conghESSO CIENCIAESOCIEDADE

A Constituição Federal de 1988 consagrou o direito ao planejamento familiar de livre decisão ao casal em razão do princípio da dignidade da pessoa humana e do princípio da paternidade responsável, vedando a integral intervenção estatal. Com o passar dos anos da promulgação da Carta Magna, regulamentou o planejamento familiar mediante Lei Ordinária de no 9.263/96, tratando a cerca do planejamento e dos métodos contraceptivos, entre eles a esterilização como método irreversível, seguindo o entendimento da não intervenção, agindo o Estado de forma subsidiária, por meio de políticas públicas visando a concretização desses direitos, seja por meio de acompanhamentos, educação em saúde e outros.

Todavia, nos dias atuais ainda se faz necessário a discussão dos direitos reprodutivos, visto que o Estado, através do poder coercitivo e das prerrogativas violam os direitos por meio de atos manifestamente ilegais indo de encontro a Constituição e todos os princípios que nela são resguardados, como foi a violência contra a dignidade de Janaína, estudo em tela.

Porém é preciso defender a dignidade humana e os preceitos nele circunscrito e não utilizar da força coercitiva para afrontar questão fundamental, sob pena de retrocesso quanto a proteção e concretização desses direitos.

\section{REFERÊNCIAS}

BRASIL. Constituição da República Federativa do Brasil. Casa Civil, Subchefia para Assuntos Jurídicos, $1988 . \quad$ Disponível em <http://www.planalto.gov.br/ccivil_03/constituicao/constituicaocompilado.htm>. Acesso em: 27 fev. 2019.

\begin{tabular}{llcccc}
. Decreto Lei no & 3.689. Código Processo Penal. Casa Civil, Subchefia para \\
\hline Assuntos & Jurídicos, & 1941. & Disponível & em & $<$
\end{tabular} http://www.planalto.gov.br/ccivil_03/decreto-lei/del3689.htm> Acesso em: 01 mai. 2019.

. Lei no 10.406. Código Civil. Casa Civil, Subchefia para Assuntos Jurídicos, 2002. Disponível em <http://www.planalto.gov.br/ccivil_03/decretolei/del2848compilado.htm> Acesso em: 01 mai. 2019. 


\section{CONQEEESSOCIENCIAESOCIEDADE \\ -}

Lei do Planejamento Familiar. Casa Civil, Subchefia para Assuntos Jurídicos, 1996. Disponível em <http://www.planalto.gov.br/ccivil_03/LEIS/L9263.htm>. Acesso em: 27 fev. 2019.

CANOTILHO; J. J. g. et al. Comentários à Constituição do Brasil. Disponível em: < file://C:/Users/Tatiane/Downloads/Comentarios-a-Constituicao-do-Brasil-GilmarMendes-Canotilho-Lenio-Ingo-etc-2013-SARAIVA.pdf> Acesso em: 21 mar. 2019.

DIAS, Maria Berenice. Manual de Direito das Famílias. 11 ed. São Paulo. Editora Revista dos Tribunais, 2016.

LENZA, Pedro. Direito Constitucional Esquematizado. 19 ed. São Paulo, Saraiva, 2015.

Martins, F. Revista Fórum. Juiz e promotor do caso Janaína atuaram na esterilização de outra mulher em Mococa. 2018 Disponível em: https://revistaforum.com.br/noticias/juiz-e-promotor-do-caso-janaina-atuaram-naesterilizacao-de-outra-mulher-em-mococa/. Acesso em: 10 jan. 2019.

MINAYO, M.C.S. O Desafio do Conhecimento: Pesquisa qualitativa em saúde. 9. ed. São Paulo: Hucitec, 2006.

RAMOS, André de Carvalho. Curso de Direitos Humanos. 5 ed. São Paulo, Saraiva Educação, 2018.

RAMOS, F. I. da S.. Análise das políticas de planejamento familiar no Brasil. 2008, Disponível em: <http://www.bdtd.uerj.br/tde_arquivos/44/TDE-2013-07-01T142636Z3478/Publico/Fernanda\%20Irene\%20da\%20Silva\%20Ramos\%20-\%20tese.pdf> Acesso em: 19 mai. 2019.

TARTUCE, Flávio. Manual de Direito Civil. 8 ed. São Paulo, Editora Método, 2018.

VIEIRA. Oscar Vilhena. Folha de S. Paulo. Justiça, ainda que tardia. 09 jun. 2018. Disponível

em: https://www1.folhauol.com.br/colunas/oscarvilhenavieira/2018/06/justica-ainda-quetardia.shtml. Acesso em: 10 jan. 2019. 